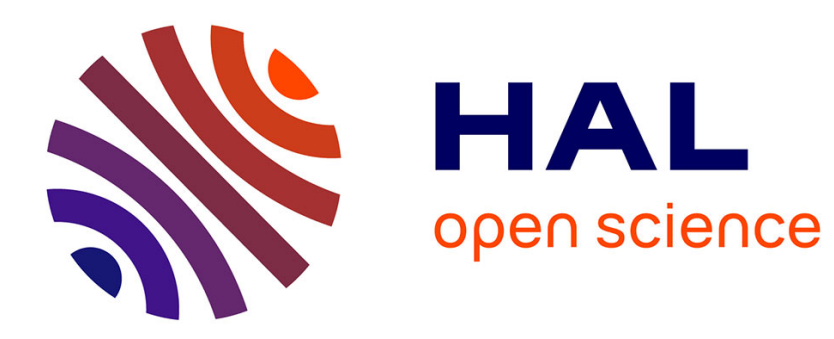

\title{
Mechanotransduction pulls the strings of matrix degradation at invadosome
}

Sanela Mrkonjic, Olivier Destaing, Corinne Albigès-Rizo

\section{To cite this version:}

Sanela Mrkonjic, Olivier Destaing, Corinne Albigès-Rizo. Mechanotransduction pulls the strings of matrix degradation at invadosome. Matrix Biology, 2017. hal-02336043

\section{HAL Id: hal-02336043 \\ https://hal.science/hal-02336043}

Submitted on 28 Oct 2019

HAL is a multi-disciplinary open access archive for the deposit and dissemination of scientific research documents, whether they are published or not. The documents may come from teaching and research institutions in France or abroad, or from public or private research centers.
L'archive ouverte pluridisciplinaire HAL, est destinée au dépôt et à la diffusion de documents scientifiques de niveau recherche, publiés ou non, émanant des établissements d'enseignement et de recherche français ou étrangers, des laboratoires publics ou privés. 
Mechanotransduction pulls the strings of matrix degradation at invadosome

Sanela Mrkonjic 1, 2, 3, Olivier Destaing 1, 2, 3 and Corinne Albiges-Rizo 1, 2, 3

1 INSERM U1209, Grenoble, F-38042, France

2 Université Grenoble Alpes, Institut Albert Bonniot, F-38042 Grenoble, France

${ }^{3}$ CNRS UMR 5309, F-38042 Grenoble, France

To whom correspondence should be addressed:

Corinne.albiges-rizo@univ-grenoble-alpes.fr

Olivier.destaing@univ-grenoble-alpes.fr 
Abstract

Degradation of the extracellular matrix is a critical step of tumor cell invasion. Both protease-dependent and -independent mechanisms have been described as alternate processes in cancer cell motility. Interestingly, some effectors of proteasedependent degradation are focalized at invadosomes and are directly coupled with contractile and adhesive machineries composed of multiple mechanosensitive proteins. This review highlights recent findings aimed at elucidating the roles of mechanosensing and mechanotransduction in directing the degradative activity at invadosomes.

\begin{abstract}
Abbreviations: BM: basement membrane; ECM: extracellular matrix; MMP: matrix metalloproteinases; $\mathrm{H}^{+}$: hydrogen ion; $\mathrm{Na}^{+}$sodium ion; VGSC: voltage gated sodium channels; $\mathrm{NHE}-1$ : $\mathrm{Na}^{+} / \mathrm{H}^{+}$exchanger 1 ; DPP4: Dipeptidyl-Peptidase; FAPa; Fibroblasts Activation Protein a; EGFR: epidermal growth factor receptor; ADAM: A Disintegrin And Metalloproteinase; HB-EGF: ligand heparin - epidermal growth factor; uPAR: plasminogen activator receptor; Src: non-receptor tyrosine kinase; $\mathrm{Ca}^{2+;}$ calcium ion; STIM1: Stromal interaction molecule 1; ER: endoplasmatic reticulum; Orai1: Calcium release-activated calcium channel protein 1; MT1-MMP: membrane-tethered matrix metalloproteinases; TRPM7: Transient receptor potential melastatin ion channel 7; Transient receptor potential canonical ion channel 1; TRPV4: Transient receptor potential vanilloid ion channel 4; TRPC1: CX3CL1: Chemoline C-X3-C motif ligand 1; CXCL16: Chemokine (C-X-C motif) ligand 16, proTNF: transmembrane tumor necrosis factor; RANKL: receptor activator of nuclear factor kappa-B ligand; DPP: Dipeptidyl-Peptidase; FAP: Fibroblasts Activation Protein; GPCR: G-protein-coupled receptors; JAK-STAT: The Janus kinase/signal transducers and activators of transcription; RGD: Arginylglycylaspartic acid; FHOD1: Formin Homology 2 Domain Containing 1; INF2: Inverted Formin, FH2 And WH2 Domain Containing; Tpm: tropomyosin; ROCK: Rho-associated protein kinase; NM II: Non-muscle myosin II; LIMK: LIM domain kinase 1; TIMP: tissue inhibitor of metalloproteinases; PI: phosphoinositide; F-BAR: Extended FCH Homology Bin1/amphiphysin/Rvs167; BAR: Bin1/amphiphysin/Rvs167; CIP4: Cdc42 Interacting Protein 4; Cdc42: Cell division control protein 42 homolog;N-WASp: Neural Wiskott-Aldrich syndrome protein; Arf-GAP: ADP-ribosylation factor GTPase-activating proteins; PIP 2 : Phosphatidylinositol 4,5-bisphosphate; PSTPIP1: Proline-SerineThreonine Phosphatase Interacting Protein 1; PACSIN 3: Protein Kinase C And Casein Kinase Substrate In Neurons 3; MHC-II: major histocompatibility complex 2; SOCE: store operated calcium entry; ER: endoplasmic reticulum; PKC: protein kinase C; Nav: Voltage-gated sodium channel; TPA : 12-O-tetradecanoylphorbol-13acetate.
\end{abstract}




\section{Introduction}

The extracellular matrix (ECM) is the non-cellular component present within all tissues and organs. It has been seen for a long time as just a structural support for tissues, but now it is very well known that ECM is highly dynamic and versatile [1]. The ECM is characterized by its large heterogeneity in terms of composition, architecture and mechanical properties. It comprises basement membrane which delimits territories between tissues by providing structural support necessary to underlie all epithelia and endothelia and by surrounding nerves, smooth muscle cells and adipocytes, [2-7], and interstitial matrix, which is primarily made by stromal cells. Basement membrane is more compact and less porous than interstitial matrix due to the different composition. The ECM, via displaying a spectrum of adhesive ligands, cytokines and matrix-bound growth factors is able to transduce signals into the cells through both its physical properties, such as stiffness, porosity, and topology, as well as its biochemical properties [1]. Importantly, the composition of the ECM is not only diverse but also highly dynamic. It varies between tissue types under physiological conditions and is often altered with pathologies and aging [8,9]. Indeed ECM within a tissue is constantly remodeled as cells deposit and reorganize the ECM by degrading and reassembling it [10]. In that respect, focalized proteolysis is essential for the remodeling of ECM in multiple physiological processes, including bone resorption, immune surveillance, organ development, and tissue communication [11]. This feature is also exploited by malignant cells to promote invasion and metastasis during cancer progression [12,13]. In case of invasion, metastasis, and tissue connexion, cells must disassemble, dissolve, deform, or perforate the ECM in order to penetrate it. Alternatively cells have to navigate the pore size which is dictated by the ECM density and cross-linking, which is known to also manifest in tissue stiffening in most solid tumors. All this is achievable due to the activity of ECM receptors such as integrins that provide physical link of cell cytoskeleton to the ECM and due to the activity of multifarious proteases present at the plasma membrane or within the ECM. This makes the ECM capable of regulating cellular functions, such as cell adhesion and invasion. These cellular functions requisite specialized structures such as focal adhesions and invadosomes that allow the interaction of the ECM to the cell [14]. Invadosome is a recent terminology that comprises invadopodia (present in tumoral cells) and podosomes (present in healthy cells) that play important roles in proteolytic 
degradation of the ECM. In many cases proteolytic degradation of the ECM is tightly linked to the activity of matrix metalloproteinases (MMPs) [15-19], chemokines and nidogens [20-23]. The activity of ECM-modifying proteins, such as MMPs is not in itself sufficient to properly degrade the ECM as this dynamic process requires synergistic association with a variety of transmembrane cellular receptors, such as integrin and growth factor receptors, which are critical for modifying cellular contractility and extracellular matrix stretching. In that respect, spatial organization and presentation of ECM-degrading components is critical in regulating this process. One method of delivering MMPs responsible for local degradation of the ECM components to sites where they are needed is via invadosomes. Invadosomes function to couple cellular contractile and degradative machineries based on both adhesive and non-adhesive receptors[24,25]. In past it has been challenging to visualize invadosome dependent matrix degradation in vivo due to their dynamicity and unpredictability. Nevertheless, recently several works have shown it using different models such as mouse tumor models, zebrafish intestinal epithelia, and $C$. elegans organogenesis [26-32].

In this review we summarize recent insights into the interplay between mechanotransduction processes and ECM degradation by the invadosomes. We address the question whether mechanical force and membrane tension are required for ECM degradation by invadosomes. Further, we describe the relationship between mechanoreceptors and protease activity in invadosomes.

\section{Repertoire of proteases in invadosomes}

Proteases found at invadosomes present the ability to target both the components of the ECM and those of transmembrane receptors present at cell surface. These include MMPs, (both secreted and membrane-tethered, such as MMP9 and MT1MMP), the ADAM family members, membrane-bound serine protease and the urokinase plasminogen activator receptor (UPAR) [33] (Fig1.).

MT1-MMP: MT1-MMP (also known as MMP14), a membrane-anchored metalloproteinase, that is a central player of invadosome-mediated ECM degradation [34]. MT1-MMP is able to cleave both the ECM components, such as fibronectin, type I, II, and III collagen, laminins, vitronectin, aggrecans and zymogens like MMP2 and MMP9 [35-39]. 
ADAMs: ADAM family members, except some soluble splice variants, are multidomain type 1 transmembrane proteins. ADAMs is capable of modulating cell-matrix interactions via two mechanisms. First, they have the ability to disengage matrix receptors from substrates through their disintegrin domain. Second, they are able to induce matrix remodeling through direct cleavage and activation of matrix proteins such as chemokines, cytokines and growth factors. The latter ones are expressed as proforms at the cell membrane including CX3CL1, CXCL16, proTNF, receptor activator of nuclear factor kappa-B ligand (RANKL), pro TGF $\alpha$ or pro heparin binding epidermal growth factor (HBEGF) via their metalloprotease activity [40]. ADAM12 is the most established ADAM in invadosomes and contributes to invadosome function at multiple levels, including ECM degradation, modulation of integrin function, and shedding to activate growth factors [41]. The sheddase activity of ADAM12 may contribute to the overall degradation activity of invadosomes [42]. A different study has shown how invadosomes in dendritic cells can switch protease activity after deletion of MT1-MMP towards ADAM17 [43].

DPP, FAP: Two transmembrane type II serine proteases of the Dipeptidyl-Peptidase (DPP) family: Fibroblasts Activation Protein (FAP, FAPa, also known as seprase) and DPP4 have also been localized to invadosomes. DPP4 and FAPa contain internal exopeptidase activity. Further, it has been shown that FAPa is complexed with DPP4 at invadosomes [44] and can be associated with $\alpha 3 \beta 1$ integrins [45]. Further, the gelatinase activity of FAPa is thought to contribute to the invadosome degradation activity following MMP1 [46].

UPAR: urokinase-type plasminogen receptor (UPAR) is reported to be colocalized with MMP-9 and MT1-MMP [33]. UPAR is highly expressed during tissue remodeling, such as in trophoblast cells in the placenta and in migrating keratinocytes in wounds [47]. Further it is able to enhance vascular smooth cell invasion by catalyzing the conversion of plasminogen to plasmin, a serine protease that degrades fibrin and other ECM constituents [48]. In addition, UPAR promotes cell adhesion through its direct interaction with the provisional ECM protein, vitronectin $[49,50]$. The lack of transmembrane and cytoplasmic domains makes UPAR incapable of direct signal transduction through the plasma membrane but its direct interaction with the integrins through the $\alpha$ chain and in complex with Src places UPAR at the heart of signal transduction and capable of altering their substrate specificity and modulating their 
signaling activity [49,51-53]. Interestingly, several signaling functions of UPAR do not require its proteolytic activity but are instead associated with cell contractility and mechanotransduction through the links with mechanotrasductive players such as integrins [53], GPCRs [54], caveolin [55] and JAK-STAT pathway [56].

In summary, by causing shedding from the cell surface, proteases may be central in regulation of the availability of adhesion proteins, growth factors, and adhesive receptors or substrates, thereby directly affecting many aspects of cell signaling and mechanotransduction process. Moreover the activity of proteases might be extended to cell signaling and not restricted exclusively to the degradative functions.

\section{Influence of ECM physical properties on degradative activity of invadosomes}

High force environment is not a prerequisite for invadosome assembly, as is the case for focal adhesions, since invadosomes are able to form even on low traction-force RGD membrane bilayers and soft gels. [14,57]. Yet, their degradative activity is highly tuned by the rigidity of the ECM, as exemplified in trophoblasts during early pregnancy where the extent of matrix degradation by trophoblast invadosomes is influenced by gelatin concentration [58]. Further, Alexander et al showed that grown cells on soft ECM substrates with a low percentage of gelatin $(0.5 \%)$ resulted not only in lower propensity for invadosome formation but also less gelatin degradation as compared to cells grown on ECMs with higher percentages of gelatin [59]. Importantly, utilization of high-density fibrillar collagen to mimic in vivo cancer environments, was sufficient to induce the formation of ECM-degrading invadosomes in tumor cells [60]. In addition to ECM stiffness, topological cues, static pressure, and injury can also induce invadosome formation [61]. For instance, it has been shown that thickness and periodicity of collagen impacts invadosome organization and activity as large fibrillar collagen organization of the ECM leads to the formation of linear invadosome [62]. Further, in osteoclasts, invadosomes organize into small and unstable sealing zones on smooth surfaces versus large stable actin rings on rough surfaces [63]. These processes are clearly functionally important as proper bone resorption for instance, requires stable sealing zones for prolonged periods of time and these necessitate rough surfaces containing microtopographic obstacles in order 
to slow down sealing-zone expansion [64]. Besides being mechanosensitive and responsive to the topographic changes of the surface, invadosome are also able to respond to changes in myosin tension and actin dynamics by modifying the organization and ability to degrade ECM $[59,65]$. Labernadie et al. showed that single invadosomes are able to generatea protrusion force that increases with ECM rigidity, further indicating the intrinsic mechanosensing ability of invadosomes [66]. This property relies on the adaptation of invadosome actin filament architecture by association with different cross-linkers, like formins and tropomyosins [67]. In that respect, formins FHOD1 and INF2 were recently found to regulate different aspects of invadosome-associated contractility through the actin cytoskeleton with FHOD1 mediating actomyosin contractility between invadosomes and INF2 regulating contractile events at individual invadosomes [68]. The collaboration of multiple types of actin filaments [69] might be specified by their tropomyosin composition such as Tpm4.2, Tpm1.8 and Tpm1.9 [70,71]. Further, periodic myosin IIA activity tunes invadosome's intrinsic stiffness throughout their lifespan [72]. The balance between actin polymerization in the core and myosin IIA activity in the ring facilitates core oscillations [73]. Recently it has been suggested that matrix rigidity differentially regulates invadosome activity through distinct ROCK1 and ROCK2-dependent signaling pathways via contractile (NM II) and non-contractile (LIMK) mechanisms [74]. Finally, invadosomes might be able to adapt the degradative machineries according to the biomechanical properties of the changing microenvironment.

\section{Force requirement in degradative activity of invadosome}

Recent studies suggest that mechanical forces play a crucial role in ECM proteolysis thereby raising the question of how this proteolytic sensitivity is achieved [75]. There are several ways in which this could be obtained. First, mechanical stimuli can tune MMPs expression and activity as exemplified by up-regulation of proteolytic activity of MMP-2, $-3,-10,-13$ and 14 , as well as increase in protein levels of MMP-2, $-3,-13$ and TIMP-2 after mechanical loading of mesenchymal stem cells leads [76]. Second, at higher stress values, cells may switch from a protease-independent to a proteasedependent invasion through the formation of invadosome-like structures [77]. Protease-dependent invasion might result from MT1-MMP processing which is increased with shear stress due to an increased activity of proconvertases by shear 
stress [78]. Moreover, MT1-MMP can not only be affected by force but it is also able to modify cellular force generation. Using MT1-MMP depleted skeletal stem cells, Tang et al. have shown that MT1-MMP-dependent proteolysis modifies cell shape which is necessary for $\beta 1$-integrin activation responsible for Rho/ROCK activity and force generation [79]. Yet, in contrast to focal adhesions, perturbation of cell contractility by the myosin II inhibitor, blebbistatin, does not block invadosome formation but only its ability to digest surrounding ECM [59]. The modification of protease activity by mechanical forces can also be indirect, as is the case for the metalloprotease ADAM12. ADAM12 metalloprotease activity leads to increased ectodomain shedding of the epidermal growth factor receptor (EGFR) ligand heparinbinding EGF-like growth factor. The released HB-EGF induces the formation of invadosomes [80]. The same work states that ectodomain shedding, resulting from the ADAM12 metalloprotease activity, is Notch-dependent and Notch activation requires proteolytic sensitivity which is achieved only under application high force environment [81]. This suggests a mechanical allostery and force requirement in the proteolytic activation of Notch for invadosomes and eventually ECM degradation. Force-induced activation of proteolysis may prove to be a new form of mechanotransduction.

In addition to local ECM degradation, invadosome generated by the anchor cell in $C$. elegans appear to generate forces that physically shift the ECM. Indeed optical highlighting of BM components using photoconversion of laminin has revealed that invadosomes of anchor cell removed the basement membrane underneath allowing uterine-vulval attachment [28,82]. The proposed model is that the gap might be initiated by MT1-MMP-dependent proteolytic process which is then able to widen by protease-independent physical displacement. In that way, limited proteolysis might make the BM more pliant for displacement. Finally, coupling of proteolytic process with changes in mechanical forces may correspond to either irreversible or reversible processes which may cue to optimize the ECM degradation and cell invasion.

\section{Membrane tension and protease activity}

Recent data highlight the importance of membrane tension in the regulation of receptors and cytosolic machineries implicated in mechanotransduction [83-87]. 
Changes in membrane composition and topography are both important regulators of biophysical properties of the membrane and therefore might influence the protease activity associated with membrane tension. Interestingly, perturbation of lipid raft formation, due to depletion or sequestering of membrane cholesterol, blocked the invadosome-mediated degradation of the gelatin matrix [88]. The recruitment of specific lipids and membrane- deforming proteins can influence the dynamics and spatial organization of invadosomes. In this respect, lipids associated with membrane curvature, such as phosphoinositides (Ptdlns), especially Ptdlns(4,5)P2 and Ptdlns(3,4,5)P3, are reported to regulate the recruitment and binding of several invadosome components [89]. Whereas membrane deforming proteins are involved in the regulation of proteases is far from elucidated. It has been reported that membrane curving protein CIP4 (Cdc42 Interacting Protein 4), which has been shown to promote invasion of MDA-MB-231 breast cancer cells [90] plays also role in endocytosis of MT1-MMP in a Src-dependent manner [91,92]. Moreover, ADAM12 is able to bind the F-BAR protein PACSIN3 which up-regulates the signaling of proHBEGF shedding induced by TPA and angiotensin II and is critical for invadosome formation [93]. Thus, protease activity is coupled to the expression of a specific lipid spectrum and a curved membrane topography and may therefore operate optimally under a specific membrane tension regime.

Membrane tension can regulate important mechanosensitive membrane invaginations such as caveolae. Indeed, caveolae respond immediately to mechanical stress by flattening into the plasma membrane [94]. Caveolae are flaskshaped invaginations enriched in cholesterol, sphingolipids, and PI(4,5)P2 [95] and contain caveolin, a membrane-embedded protein that undergoes oligomerization to generate curvature [96]. Calveolae have been also shown to be involved in proteases, such as MT1-MMP, trafficking [97,98]. MT1-MMP interacts with the phosphorylated form of caveolin [99] and caveolae are required for proper MT1-MMP localization and degradation during cell invasion [97,100,101]. Calveolae are not the only case in which membrane tension regulates the cell trafficking. It has been shown that membrane tension regulates the balance between exocytosis and endocytosis in a number of systems [102,103]. 
Interestingly, previously mentioned UPAR has been recently described as a regulator of membrane tension [104], but it may also function by inducing caveolae assembly [105]. This process depends on ligand- independent integrin signaling, occurring independently of acto-myosin pulling forces but requiring integrin engagement and activation[104].

When the membrane reservoir is reduced such as during cell spreading, there is the two-fold increase in membrane tension, followed by the activation of exocytosis [106]. High membrane tension also impairs the endocytosis [107] which means that membrane tension variations are ensuring the full capacity of the membrane reservoir.

\section{Mechanosensitive calcium channels and proteases activity in invadosomes}

Changes in membrane tension and curvature alter the conformation and distribution of mechanosensitive ion channels [108]. Most of the mechanosensitive ion channels are $\mathrm{Ca}^{2+}$ permeating ion channels $[109,110]$. Calcium and signaling molecules downstream of the ubiquitous secondary messenger calcium are required for invadosome formation and ECM degradation [59,111-113]. Moreover proteases like UPAR induce the mobilization of intracellular calcium [114]. However, the role of calcium signaling in degradative activity of invadosome is just emerging. Interestingly, the $\mathrm{Ca}^{2+}$ concentration can fluctuate greatly when a cell sense different substrate rigidities [115]. This fluctuation is controlled by mechanosensitive ion channels, which are part of the intrinsic force measurement system that generates $\mathrm{Ca}^{2+}$ gradients and promotes the entire migration process [116].

Most cells mobilize their $\mathrm{Ca}^{2+}$ signals via the $\mathrm{Ca}^{2+}$ entry across the plasma membrane and/or the $\mathrm{Ca}^{2+}$ traffic between cytoplasm and intracellular stores such as endoplasmic reticulum (ER) [117]. $\mathrm{Ca}^{2+}$ entry across the plasma membrane occurs via several distinct pathways, including voltage-operated $\mathrm{Ca}^{2+}$ channels (VOCCs), store-operated $\mathrm{Ca}^{2+}$ (SOC) channels and transient receptor potential channels (TRP) [118-120]. Many reports have revealed how $\mathrm{Ca}^{2+}$ forms gradients via TRPM7, channel localized in invadosomes and activated by membrane stretching or under shear stress [121,122]. TRPM7 consists in the fusion between a cation channel and a functional C-terminal serine/threonine protein kinase domain [123] and controls 
actomyosin dynamics by phosphorylation of tropomodulin 1 and MHC-II isoforms AC $[124,125]$. Activation of TRPM7 by bradykinin leads to a $\mathrm{Ca}^{2+}$ - and kinasedependent interaction with the actomyosin cytoskeleton and transformation of focal adhesions into invadosomes in a kinase-dependent mechanism [125]. TRPM7 silencing also increases the ratio of MMPs/TIMPs by increasing MMP-13 expression and decreasing TIMP-1 and TIMP-2 levels [126]. Blocking of TRPM7 also decreased MMP-2 protein expression [127]. However ER might be also the source of calcium necessary for invadosome function. Sun et al. have reported that calcium oscillations through the store-operated $\mathrm{Ca}^{2+}$ channels Stim and Orai stimulate melanoma invasion by promoting invadosome assembly and ECM degradation by activating Src. Further, Stim1 and Orai1 might regulate the proteolysis activity of individual invadosomes by impacting the recycling of MT1-MMP [111]. However Stim1 and Orai can heteromultimerise with members of mechanosensitive channels such as TRPC1 and TRPV4. Stim1 translocates TRPC1 into the cell membrane to activate calcium influx and only by the help of Stim1, TRPC1 becomes a functional channel $[128,129]$. It has been shown that actin and microtubule remodeling results in inhibition of store operated calcium entry (SOCE) [130], which supports that actomyosin is able to modulate ER dynamics $[131,132]$. By compartmentalizing $\mathrm{Ca}^{2+}$ signals into spatio-temporal patterns, cells are able to activate selective downstream signaling events at a defined time and subcellular location. Altogether these data bring insight into the importance of spatiotemporal organization of $\mathrm{Ca}^{2+}$ signals for the focalized degradative activity of invadosomes.

\section{Mechanosensitive sodium channels as protease regulators through $\mathrm{pH}$ and osmotic pressure oscillations in invadosomes}

The low extracellular $\mathrm{pH}$ of tumoral environment raises the question whether mechanical force can affect BM degradation through oscillations in $\mathrm{pH}$. In that respect, mechanosensitive sodium channels can locally modulate tumoral $\mathrm{pH}$, which tends to be quite acidic [133-135]. Moreover sodium channels are involved in regulation of osmotic pressure [136] and consequently membrane tension. It has been reported that protease activity is dependent on $\mathrm{Na}^{+} / \mathrm{H}^{+}$exchanger 1 (NHE1)driven extracellular acidification during cell invasion $[137,138]$. Consistently, NHE-1 has been described to regulate invadosome-mediated matrix degradation through 
acidification of the nanospace surrounding invadosome $[139,140]$. Further, NHE1 has been shown to be activated in response to stretch [141] and osmotic stress in a PKCdependent manner [142]. Further, membrane stretching increases the magnitude and kinetics of voltage-activated $\mathrm{Na}^{+}$currents [143,144]. Additionally, gating of voltage gated sodium channel (VGSC) Nav1.5 [145] is involved in breast cancer invasiveness by increasing the activity of acidic cysteine cathepsins through the acidification of the pericellular microenvironment $[146,147]$. Nav1.5 might be sensitive to cell tension by interacting with NHE-1 in caveolin-1-localized in invadosomes [148]. Nav1.5 is also responsible for the allosteric modulation of NHE-1, thus enhancing the proteolytic activity of invadosomes. By contrast, VGSC blockers decrease the invasive potential of cell by reducing the activity of proteases such as cathepsin $E$, kallikrein-10 and MMP-7, as well as total MMP[149]. Another stretch activated sodium channel Nav1.6 has been also reported to affect invadosomes activity since its blockade prevents ECM degradation by macrophages and melanoma cells [150]. Not only ion channels can affect invadosome dependent matrix degradation but the MMP proteolysis can affect the clustering of the ion channels such as in the case of MMP9 proteolysis that has been shown also to regulate the cell surface levels of some VGSC [151].

\section{Future directions}

Clinical trials that targeted MMPs in late-stage cancer patients failed to increase survival, likely due to the lack of specificity of inhibitors [15,152]. Better understanding of the regulation of proteases by forces and mechanosensitive players at invadosomes could improve the specificity of these drugs. Ion channels are specifically interesting targets since many of them have already specific activators and inhibitors and several of them have already been linked to other ECM receptors such as integrins. We also propose to change the focus of ion channels from simply ion permeating devices into more complex machinery that links different signaling complexes (such as mechanosensitive complexes with adhesion system) while at the same time fine tunes them by permeating ions as secondary messengers. The complexity of these processes in cell invasion is just emerging.

The next step should be also to investigate if and how the change of the environment during ECM degradation acts as a feedback for MMP activity tuning. It is thinkable 
that change of environmental force upon ECM degradation might act as retro-control loop to down regulate ECM membrane degradation.

\section{Aknowledgements:}

We thank Eva Faurobert and Kate Miroshnikova for manuscript reading and suggestions. SM was supported by ARC grant and The Marie Skłodowska-Curie Actions in Horizon 2020 . The CAR team is supported by LLNC as "Equipe labellisée Ligue 2014", ANR and ARC.

\section{References}

[1] R.O. Hynes, The extracellular matrix: not just pretty fibrils., Science. 326 (2009) 1216-9. doi:10.1126/science.1176009.

[2] A. Glentis, V. Gurchenkov, D.M. Vignjevic, Assembly, heterogeneity, and breaching of the basement membranes, Cell Adhes. Migr. 8 (2014) 236-245. doi:10.4161/cam.28733.

[3] R. Kalluri, Basement membranes: structure, assembly and role in tumour angiogenesis., Nat. Rev. Cancer. 3 (2003) 422-433. doi:10.1038/nrc1094.

[4] P.D. Yurchenco, J.C. Schittny, Molecular architecture of basement membranes., FASEB J. 4 (1990) 1577-90. doi:10.1096/fj.1530-6860.

[5] P.D. Yurchenco, Y.S. Cheng, H. Colognato, Laminin forms an independent network in basement membranes, J. Cell Biol. 117 (1992) 1119-1133. doi:10.1083/jcb.117.5.1119.

[6] R.O. Hynes, The evolution of metazoan extracellular matrix, J. Cell Biol. 196 (2012) 671-679. doi:10.1083/jcb.201109041.

[7] R. lozzo, Basement membrane proteoglycans: from cellar to ceiling., Nat. Rev. Mol. Cell Biol. 6 (2005) 646-56. doi:10.1038/nrm1702.

[8] M. Schoumacher, D. Louvard, D. Vignjevic, Cytoskeleton networks in basement membrane transmigration, Eur. J. Cell Biol. 90 (2011) 93-99. 
doi:10.1016/j.ejcb.2010.05.010.

[9] L.C. Kelley, L.L. Lohmer, E.J. Hagedorn, D.R. Sherwood, Traversing the basement membrane in vivo: A diversity of strategies, J. Cell Biol. 204 (2014) 291-302. doi:10.1083/jcb.201311112.

[10] R.G. Rowe, S.J. Weiss, Breaching the basement membrane: who, when and how?, Trends Cell Biol. 18 (2008) 560-574. doi:10.1016/j.tcb.2008.08.007.

[11] M. Gimona, R. Buccione, S.A. Courtneidge, S. Linder, Assembly and biological role of podosomes and invadopodia, Curr. Opin. Cell Biol. 20 (2008) 235-241. doi:10.1016/j.ceb.2008.01.005.

[12] F. Sabeh, R. Shimizu-Hirota, S.J. Weiss, Protease-dependent versus independent cancer cell invasion programs: three-dimensional amoeboid movement revisited., J. Cell Biol. 185 (2009) 11-9. doi:10.1083/jcb.200807195.

[13] D.A. Murphy, S.A. Courtneidge, The "ins" and "outs" of podosomes and invadopodia: characteristics, formation and function., Nat. Rev. Mol. Cell Biol. 12 (2011) 413-26. doi:10.1038/nrm3141.

[14] C. Albiges-Rizo, O. Destaing, B. Fourcade, E. Planus, M.R. Block, Actin machinery and mechanosensitivity in invadopodia, podosomes and focal adhesions., J. Cell Sci. 122 (2009) 3037-3049. doi:10.1242/jcs.052704.

[15] C.M. Overall, O. Kleifeld, Towards third generation matrix metalloproteinase inhibitors for cancer therapy., Br. J. Cancer. 94 (2006) 941-6. doi:10.1038/sj.bjc.6603043.

[16] K. Kessenbrock, V. Plaks, Z. Werb, Matrix Metalloproteinases: Regulators of the Tumor Microenvironment, Cell. 141 (2010) 52-67. doi:10.1016/j.cell.2010.03.015.

[17] P. Vihinen, V.-M. Kähäri, Matrix metalloproteinases in cancer: prognostic markers and therapeutic targets., Int. J. Cancer. 99 (2002) 157-66. doi:10.1002/ijc.10329.

[18] S. Valastyan, R.A. Weinberg, Tumor metastasis: Molecular insights and evolving paradigms, Cell. 147 (2011) 275-292. doi:10.1016/j.cell.2011.09.024. 
[19] G. Shay, C.C. Lynch, B. Fingleton, Moving targets: Emerging roles for MMPs in cancer progression and metastasis, Matrix Biol. 44-46 (2015) 200-206. doi:http://dx.doi.org/10.1016/j.matbio.2015.01.019.

[20] A. Page-McCaw, A.J. Ewald, Z. Werb, Matrix metalloproteinases and the regulation of tissue remodelling., Nat. Rev. Mol. Cell Biol. 8 (2007) 221-33. doi:10.1038/nrm2125.

[21] C.M. Overall, C.P. Blobel, In search of partners: linking extracellular proteases to substrates., Nat. Rev. Mol. Cell Biol. 8 (2007) 245-57. doi:10.1038/nrm2120.

[22] S. Schenk, E. Hintermann, M. Bilban, N. Koshikawa, C. Hojilla, R. Khokha, V. Quaranta, Binding to EGF receptor of a laminin-5 EGF-like fragment liberated during MMP-dependent mammary gland involution, J. Cell Biol. 161 (2003) 197-209. doi:10.1083/jcb.200208145.

[23] S. Schenk, V. Quaranta, Tales from the crypt[ic] sites of the extracellular matrix, Trends Cell Biol. 13 (2003) 366-375. doi:10.1016/S09628924(03)00129-6.

[24] O. Destaing, M.R. Block, E. Planus, C. Albiges-Rizo, Invadosome regulation by adhesion signaling, Curr. Opin. Cell Biol. 23 (2011) 597-606. doi:10.1016/j.ceb.2011.04.002.

[25] O. Destaing, C. Petropoulos, C. Albiges-Rizo, Coupling between acto-adhesive machinery and ECM degradation in invadosomes, Cell Adhes. Migr. 8 (2014) 256-262. doi:10.4161/cam.28558.

[26] M. Roh-Johnson, J.J. Bravo-Cordero, A. Patsialou, V.P. Sharma, P. Guo, H. Liu, L. Hodgson, J. Condeelis, Macrophage contact induces RhoA GTPase signaling to trigger tumor cell intravasation., Oncogene. 33 (2014) 4203-12. doi:10.1038/onc.2013.377.

[27] M.A. Eckert, T.M. Lwin, A.T. Chang, J. Kim, E. Danis, L. Ohno-Machado, J. Yang, Twist1-Induced Invadopodia Formation Promotes Tumor Metastasis, Cancer Cell. 19 (2011) 372-386. doi:10.1016/j.ccr.2011.01.036.

[28] E.J. Hagedorn, J.W. Ziel, M.A. Morrissey, L.M. Linden, Z. Wang, Q. Chi, S.A. 
Johnson, D.R. Sherwood, The netrin receptor DCC focuses invadopodia-driven basement membrane transmigration in vivo, J. Cell Biol. 201 (2013) 903-913. doi:10.1083/jcb.201301091.

[29] F. Liu, D. Lagares, K.M. Choi, L. Stopfer, A. Marinković, V. Vrbanac, C.K. Probst, S.E. Hiemer, T.H. Sisson, J.C. Horowitz, I.O. Rosas, L.E. Fredenburgh, C. Feghali-Bostwick, X. Varelas, A.M. Tager, D.J. Tschumperlin, Mechanosignaling through YAP and TAZ drive fibroblast activation and fibrosis., Am. J. Physiol. Lung Cell. Mol. Physiol. 55906 (2014) ajplung.00300.2014. doi:10.1152/ajplung.00300.2014.

[30] L.L. Lohmer, L.C. Kelley, E.J. Hagedorn, D.R. Sherwood, Invadopodia and basement membrane invasion in vivo, Cell Adhes. Migr. 8 (2014) 246-255. doi:10.4161/cam.28406.

[31] C. Seiler, G. Davuluri, J. Abrams, F.J. Byfield, P.A. Janmey, M. Pack, Smooth Muscle Tension Induces Invasive Remodeling of the Zebrafish Intestine, PLoS Biol. 10 (2012). doi:10.1371/journal.pbio.1001386.

[32] Z.N. Zhou, V.P. Sharma, B.T. Beaty, M. Roh-Johnson, E.A. Peterson, N. Van Rooijen, P.A. Kenny, H.S. Wiley, J.S. Condeelis, J.E. Segall, Autocrine HBEGF expression promotes breast cancer intravasation, metastasis and macrophageindependent invasion in vivo., Oncogene. 33 (2014) 3784-93. doi:10.1038/onc.2013.363.

[33] E. Furmaniak-Kazmierczak, S.W. Crawley, R.L. Carter, D.H. Maurice, G.P. Côté, Formation of extracellular matrix-digesting invadopodia by primary aortic smooth muscle cells, Circ. Res. 100 (2007) 1328-1336. doi:10.1161/CIRCRESAHA.106.147744.

[34] R. Poincloux, F. Lizárraga, P. Chavrier, Matrix invasion by tumour cells: a focus on MT1-MMP trafficking to invadopodia., J. Cell Sci. 122 (2009) 3015-3024. doi:10.1242/jcs.034561.

[35] I. Yana, S.J. Weiss, Regulation of membrane type-1 matrix metalloproteinase activation by proprotein convertases., Mol. Biol. Cell. 11 (2000) 2387-401. doi:10.1091/mbc.11.7.2387. 
[36] E. Ohuchi, K. Imai, Y. Fujii, H. Sato, M. Seiki, Y. Okada, Membrane type 1 matrix metalloproteinase digests interstitial collagens and other extracellular matrix macromolecules, J. Biol. Chem. 272 (1997) 2446-2451. doi:10.1074/jbc.272.4.2446.

[37] A.J. Fosang, K. Last, Y. Fujii, M. Seiki, Y. Okada, Membrane-type 1 MMP (MMP-14) cleaves at three sites in the aggrecan interglobular domain, FEBS Lett. 430 (1998) 186-190. doi:10.1016/S0014-5793(98)00667-X.

[38] N. Koshikawa, G. Giannelli, V. Cirulli, K. Miyazaki, V. Quaranta, Role of cell surface metalloprotease MT1-MMP in epithelial cell migration over laminin-5, J. Cell Biol. 148 (2000) 615-624. doi:10.1083/jcb.148.3.615.

[39] E.I. Deryugina, B. Ratnikov, E. Monosov, T.I. Postnova, R. DiScipio, J.W. Smith, a Y. Strongin, MT1-MMP initiates activation of pro-MMP-2 and integrin alphavbeta3 promotes maturation of MMP-2 in breast carcinoma cells., Exp. Cell Res. 263 (2001) 209-223. doi:10.1006/excr.2000.5118.

[40] G. Murphy, The ADAMs: signalling scissors in the tumour microenvironment., Nat. Rev. Cancer. 8 (2008) 929-941. doi:10.1038/nrc2459.

[41] M. Kveiborg, R. Albrechtsen, J.R. Couchman, U.M. Wewer, Cellular roles of ADAM12 in health and disease, Int. J. Biochem. Cell Biol. 40 (2008) 16851702. doi:10.1016/j.biocel.2008.01.025.

[42] R. Albrechtsen, D. Stautz, A. Sanjay, M. Kveiborg, U.M. Wewer, Extracellular engagement of ADAM12 induces clusters of invadopodia with localized ectodomain shedding activity, Exp. Cell Res. 317 (2011) 195-209. doi:10.1016/j.yexcr.2010.10.003.

[43] M.A. West, A.R. Prescott, M.C. Kui, Z. Zhou, S. Rose-John, J. Scheller, C. Watts, TLR ligand-induced podosome disassembly in dendritic cells is ADAM17 dependent, J. Cell Biol. 182 (2008) 993-1005. doi:10.1083/jcb.200801022.

[44] G. Ghersi, Q. Zhao, M. Salamone, Y. Yeh, S. Zucker, W.T. Chen, The protease complex consisting of dipeptidyl peptidase IV and seprase plays a role in the migration and invasion of human endothelial cells in collagenous matrices, 
Cancer Res. 66 (2006) 4652-4661. doi:10.1158/0008-5472.CAN-05-1245.

[45] S.C. Mueller, G. Ghersi, S.K. Akiyama, Q.X.A. Sang, L. Howard, M. PineiroSanchez, H. Nakahara, Y. Yeh, W.T. Chen, A novel protease-docking function of integrin at invadopodia, J. Biol. Chem. 274 (1999) 24947-24952. doi:10.1074/jbc.274.35.24947.

[46] V.J. Christiansen, K.W. Jackson, K.N. Lee, P.A. McKee, Effect of fibroblast activation protein and alpha2-antiplasmin cleaving enzyme on collagen types I, III, and IV., Arch. Biochem. Biophys. 457 (2007) 177-86. doi:10.1016/j.abb.2006.11.006.

[47] H. Solberg, M. Ploug, G. Høyer-Hansen, B.S. Nielsen, L.R. Lund, The murine receptor for urokinase-type plasminogen activator is primarily expressed in tissues actively undergoing remodeling., J. Histochem. Cytochem. 49 (2001) 237-246. doi:10.1177/002215540104900211.

[48] F. Blasi, P. Carmeliet, uPAR: a versatile signalling orchestrator., Nat. Rev. Mol. Cell Biol. 3 (2002) 932-943. doi:10.1038/nrm977.

[49] Y. Wei, D.A. Waltz, N. Rao, R.J. Drummond, S. Rosenberg, H.A. Chapman, Identification of the urokinase receptor as an adhesion receptor for vitronectin, J. Biol. Chem. 269 (1994) 32380-32388.

[50] C.D. Madsen, G.M.S. Ferraris, A. Andolfo, O. Cunningham, N. Sidenius, UPARinduced cell adhesion and migration: Vitronectin provides the key, J. Cell Biol. 177 (2007) 927-939. doi:10.1083/jcb.200612058.

[51] N. Montuori, M.V. Carriero, S. Salzano, G. Rossi, P. Ragno, The cleavage of the urokinase receptor regulates its multiple functions., J. Biol. Chem. 277 (2002) 46932-46939. doi:10.1074/jbc.M207494200.

[52] J. Bohuslav, V. Horejsi, C. Hansmann, J. Stockl, U.H. Weidle, O. Majdic, I. Bartke, W. Knapp, H. Stockinger, Urokinase plasminogen activator receptor, beta 2-integrins, and Src-kinases within a single receptor complex of human monocytes, J Exp Med. 181 (1995) 1381-1390.

[53] Y. Wei, M. Lukashev, D.I. Simon, S.C. Bodary, S. Rosenberg, M. V Doyle, H. a 
Chapman, Regulation of integrin function by the urokinase receptor., Science. 273 (1996) 1551-1555. doi:10.1126/science.273.5281.1551.

[54] M. Resnati, I. Pallavicini, J.M. Wang, J. Oppenheim, C.N. Serhan, M. Romano, F. Blasi, The fibrinolytic receptor for urokinase activates the $G$ protein-coupled chemotactic receptor FPRL1/LXA4R., Proc. Natl. Acad. Sci. U. S. A. 99 (2002) 1359-64. doi:10.1073/pnas.022652999.

[55] Y. Wei, X. Yang, Q. Liu, J.A. Wilkins, H.A. Chapman, A Role for Caveolin and the Urokinase Receptor in Integrin-mediated Adhesion and Signaling, J. Cell Biol. 144 (1999) 1285-1294. doi:10.1083/jcb.144.6.1285.

[56] Y. Koshelnick, M. Ehart, P. Hufnagl, P.C. Heinrich, B.R. Binder, Urokinase receptor is associated with the components of the JAK1/STAT1 signaling pathway and leads to activation of this pathway upon receptor clustering in the human kidney epithelial tumor cell line TCL-598, J. Biol. Chem. 272 (1997) 28563-28567. http://www.google.com/search?client=safari\&rls=enus\&q=Urokinase+receptor+is+associated+with+the+components+of+the+JAK1 +STAT1+signaling+pathway+and+leads+to+activation+of+this+pathway+upon +receptor+clustering+in+the+human+kidney+epithelial+tumor+cell+line.

[57] C. han Yu, N. Rafiq, A. Krishnasamy, K. Hartman, G. Jones, A. Bershadsky, M. Sheetz, Integrin-matrix clusters form podosome-like adhesions in the absence of traction forces, Cell Rep. 5 (2013) 1456-1468. doi:10.1016/j.celrep.2013.10.040.

[58] A. Patel, P.R. Dash, Formation of atypical podosomes in extravillous trophoblasts regulates extracellular matrix degradation, Eur. J. Cell Biol. 91 (2012) 171-179. doi:10.1016/j.ejcb.2011.11.006.

[59] N.R. Alexander, K.M. Branch, A. Parekh, E.S. Clark, I.C. Iwueke, S.A. Guelcher, A.M. Weaver, Extracellular Matrix Rigidity Promotes Invadopodia Activity, Curr. Biol. 18 (2008) 1295-1299. doi:10.1016/j.cub.2008.07.090.

[60] V. V. Artym, S. Swatkoski, K. Matsumoto, C.B. Campbell, R.J. Petrie, E.K. Dimitriadis, X. Li, S.C. Mueller, T.H. Bugge, M. Gucek, K.M. Yamada, Dense fibrillar collagen is a potent inducer of invadopodia via a specific signaling 
network, J. Cell Biol. 208 (2015) 331-350. doi:10.1083/jcb.201405099.

[61] N.Y. Kim, J.C. Kohn, J. Huynh, S.P. Carey, B.N. Mason, G. Vouyouka, C.A. Reinhart-king, Biophysical Induction of Vascular Smooth Muscle Cell Podosomes, (2015) 1-12. doi:10.1371/journal.pone.0119008.

[62] A. Juin, J. Di Martino, B. Leitinger, E. Henriet, A.S. Gary, L. Paysan, J. Bomo, G. Baffet, C. Gauthier-Rouvi??re, J. Rosenbaum, V. Moreau, F. Saltel, Discoidin domain receptor 1 controls linear invadosome formation via a Cdc42Tuba pathway, J. Cell Biol. 207 (2014) 517-533. doi:10.1083/jcb.201404079.

[63] D. Geblinger, L. Addadi, B. Geiger, Nano-topography sensing by osteoclasts., J. Cell Sci. 123 (2010) 1503-1510. doi:10.1242/jcs.060954.

[64] D. Geblinger, C. Zink, N.D. Spencer, L. Addadi, B. Geiger, Effects of surface microtopography on the assembly of the osteoclast resorption apparatus., J. R. Soc. Interface. 9 (2012) 1599-608. doi:10.1098/rsif.2011.0659.

[65] O. Collin, S. Na, F. Chowdhury, M. Hong, M.E. Shin, F. Wang, N. Wang, SelfOrganized Podosomes Are Dynamic Mechanosensors, Curr. Biol. 18 (2008) 1288-1294. doi:10.1016/j.cub.2008.07.046.

[66] A. Labernadie, A. Bouissou, P. Delobelle, S. Balor, R. Voituriez, A. Proag, I. Fourquaux, C. Thibault, C. Vieu, R. Poincloux, G.M. Charrière, I. MaridonneauParini, Protrusion force microscopy reveals oscillatory force generation and mechanosensing activity of human macrophage podosomes., Nat. Commun. 5 (2014) 5343. doi:10.1038/ncomms6343.

[67] Y. Tseng, T.P. Kole, J.S.H. Lee, E. Fedorov, S.C. Almo, B.W. Schafer, D. Wirtz, How actin crosslinking and bundling proteins cooperate to generate an enhanced cell mechanical response, Biochem. Biophys. Res. Commun. 334 (2005) 183-192. doi:10.1016/j.bbrc.2005.05.205.

[68] L. Panzer, L. Trübe, M. Klose, B. Joosten, J. Slotman, A. Cambi, S. Linder, The formins FHOD1 and INF2 regulate inter- and intra-structural contractility of podosomes., J. Cell Sci. (2015). doi:10.1242/jcs.177691.

[69] C. Luxenburg, D. Geblinger, E. Klein, K. Anderson, D. Hanein, B. Geiger, L. 
Addadi, The architecture of the adhesive apparatus of cultured osteoclasts: From podosome formation to sealing zone assembly, PLoS One. 2 (2007). doi:10.1371/journal.pone.0000179.

[70] B.K. McMichael, P. Kotadiya, T. Singh, L.S. Holliday, B.S. Lee, Tropomyosin isoforms localize to distinct microfilament populations in osteoclasts, Bone. 39 (2006) 694-705. doi:10.1016/j.bone.2006.04.031.

[71] P.W. Gunning, E.C. Hardeman, P. Lappalainen, D.P. Mulvihill, Tropomyosin master regulator of actin filament function in the cytoskeleton., J. Cell Sci. (2015) 1-10. doi:10.1242/jcs.172502.

[72] A. Labernadie, C. Thibault, C. Vieu, I. Maridonneau-Parini, G.M. Charrière, Dynamics of podosome stiffness revealed by atomic force microscopy., Proc. Natl. Acad. Sci. U. S. A. 107 (2010) 21016-21021. doi:10.1073/pnas.1007835107.

[73] K. van den Dries, M.B.M. Meddens, S. de Keijzer, S.C. Shekhar, V. Subramaniam, C.G. Figdor, A. Cambi, Interplay between myosin IIA-mediated contractility and actin network integrity orchestrates podosome composition and oscillations, Nat. Commun. 4 (2013) 1412. doi:10.1038/ncomms2402.

[74] R.J. Jerrell, A. Parekh, Matrix rigidity differentially regulates invadopodia activity through ROCK1 and ROCK2, Biomaterials. 84 (2016) 119-129. doi:10.1016/j.biomaterials.2016.01.028.

[75] R. Kirmse, H. Otto, T. Ludwig, Interdependency of cell adhesion, force generation and extracellular proteolysis in matrix remodeling., J. Cell Sci. 124 (2011) 1857-1866. doi:10.1242/jcs.079343.

[76] G. Kasper, J.D. Glaeser, S. Geissler, A. Ode, J. Tuischer, G. Matziolis, C. Perka, G.N. Duda, Matrix metalloprotease activity is an essential link between mechanical stimulus and mesenchymal stem cell behavior., Stem Cells. 25 (2007) 1985-1994. doi:10.1634/stemcells.2006-0676.

[77] A. Aung, Y.N. Seo, S. Lu, Y. Wang, C. Jamora, J.C. Del Álamo, S. Varghese, 3D traction stresses activate protease-dependent invasion of cancer cells., Biophys. J. 107 (2014) 2528-37. doi:10.1016/j.bpj.2014.07.078. 
[78] H. Kang, C.L. Duran, C. a. Abbey, R.R. Kaunas, K.J. Bayless, Fluid shear stress promotes proprotein convertase-dependent activation of MT1-MMP., Biochem. Biophys. Res. Commun. 460 (2015) 596-602. doi:10.1016/j.bbrc.2015.03.075.

[79] Y. Tang, R.G. Rowe, E. Botvinick, A. Kurup, A. Putnam, M. Seiki, V. Weaver, E. Keller, S. Goldstein, J. Dai, D. Begun, T. Saunders, S.J. Weiss, MT1-MMPDependent Control of Skeletal Stem Cell Commitment via a ??1Integrin/YAP/TAZ Signaling Axis, Dev. Cell. 25 (2013) 402-416. doi:10.1016/j.devcel.2013.04.011.

[80] B. Díaz, A. Yuen, S. lizuka, S. Higashiyama, S.A. Courtneidge, Notch increases the shedding of HB-EGF by ADAM12 to potentiate invadopodia formation in hypoxia, J. Cell Biol. 201 (2013) 279-292. doi:10.1083/jcb.201209151.

[81] W.R. Gordon, B. Zimmerman, L. He, L.J. Miles, J. Huang, K. Tiyanont, D.G. McArthur, J.C. Aster, N. Perrimon, J.J. Loparo, S.C. Blacklow, Mechanical Allostery: Evidence for a Force Requirement in the Proteolytic Activation of Notch, Dev. Cell. 33 (2015) 729-736. doi:10.1016/j.devcel.2015.05.004.

[82] S. Ihara, E.J. Hagedorn, M. a Morrissey, Q. Chi, F. Motegi, J.M. Kramer, D.R. Sherwood, Basement membrane sliding and targeted adhesion remodels tissue boundaries during uterine-vulval attachment in Caenorhabditis elegans., Nat. Cell Biol. 13 (2011) 641-651. doi:10.1038/ncb2233.

[83] E.L. Batchelder, G. Hollopeter, C. Campillo, X. Mezanges, E.M. Jorgensen, P. Nassoy, P. Sens, J. Plastino, Membrane tension regulates motility by controlling lamellipodium organization., Proc. Natl. Acad. Sci. U. S. A. 108 (2011) 11429-11434. doi:10.1073/pnas.1010481108.

[84] K. Tsujita, S. Suetsugu, N. Sasaki, M. Furutani, T. Oikawa, T. Takenawa, Coordination between the actin cytoskeleton and membrane deformation by a novel membrane tubulation domain of $\mathrm{PCH}$ proteins is involved in endocytosis, J. Cell Biol. 172 (2006) 269-279. doi:10.1083/jcb.200508091.

[85] K. Tsujita, T. Takenawa, T. Itoh, Feedback regulation between plasma 
membrane tension and membrane-bending proteins organizes cell polarity during leading edge formation., Nat. Cell Biol. 17 (2015) 749-758. doi:10.1038/ncb3162.

[86] M.P. Sheetz, J. Dai, Modulation of membrane dynamics and cell motility by membrane tension, Trends Cell Biol. 6 (1996) 85-89. doi:10.1016/09628924(96)80993-7.

[87] A.D. Lieber, S. Yehudai-Resheff, E.L. Barnhart, J.A. Theriot, K. Keren, Membrane tension in rapidly moving cells is determined by cytoskeletal forces, Curr. Biol. 23 (2013) 1409-1417. doi:10.1016/j.cub.2013.05.063.

[88] H. Yamaguchi, Y. Takeo, S. Yoshida, Z. Kouchi, Y. Nakamura, K. Fukami, Lipid rafts and caveolin-1 are required for invadopodia formation and extracellular matrix degradation by human breast cancer cells, Cancer Res. 69 (2009) 8594-8602. doi:10.1158/0008-5472.CAN-09-2305.

[89] T. Oikawa, T. Itoh, T. Takenawa, Sequential signals toward podosome formation in NIH-src cells, J. Cell Biol. 182 (2008) 157-169. doi:10.1083/jcb.200801042.

[90] C.S. Pichot, C. Arvanitis, S.M. Hartig, S.A. Jensen, J. Bechill, S. Marzouk, J. Yu, J.A. Frost, S.J. Corey, Cdc42-interacting protein 4 promotes breast cancer cell invasion and formation of invadopodia through activation of N-WASp, Cancer Res. 70 (2010) 8347-8356. doi:10.1158/0008-5472.CAN-09-4149.

[91] J. Hu, A. Mukhopadhyay, P. Truesdell, H. Chander, U.K. Mukhopadhyay, A.S. Mak, A.W.B. Craig, Cdc42-interacting protein 4 is a Src substrate that regulates invadopodia and invasiveness of breast tumors by promoting MT1-MMP endocytosis., J. Cell Sci. 124 (2011) 1739-51. doi:10.1242/jcs.078014.

[92] X. Wu, B. Gan, Y. Yoo, J.L. Guan, FAK-Mediated Src phosphorylation of endophilin A2 inhibits endocytosis of MT1-MMP and promotes ECM degradation, Dev. Cell. 9 (2005) 185-196. doi:10.1016/j.devcel.2005.06.006.

[93] S. Mori, M. Tanaka, D. Nanba, E. Nishiwaki, H. Ishiguro, S. Higashiyama, N. Matsuura, PACSIN3 Binds ADAM12/Meltrin ?? and Up-regulates Ectodomain Shedding of Heparin-binding Epidermal Growth Factor-like Growth Factor, J. 
Biol. Chem. 278 (2003) 46029-46034. doi:10.1074/jbc.M306393200.

[94] B. Sinha, D. K??ster, R. Ruez, P. Gonnord, M. Bastiani, D. Abankwa, R. V. Stan, G. Butler-Browne, B. Vedie, L. Johannes, N. Morone, R.G. Parton, G. Raposo, P. Sens, C. Lamaze, P. Nassoy, Cells respond to mechanical stress by rapid disassembly of caveolae, Cell. 144 (2011) 402-413. doi:10.1016/j.cell.2010.12.031.

[95] A. Fujita, J. Cheng, K. Tauchi-Sato, T. Takenawa, T. Fujimoto, A distinct pool of phosphatidylinositol 4,5-bisphosphate in caveolae revealed by a nanoscale labeling technique, Proc Natl Acad Sci U S A. 106 (2009) 9256-9261. doi:10.1073/pnas.0900216106.

[96] K.G. Rothberg, J.E. Heuser, W.C. Donzell, Y.S. Ying, J.R. Glenney, R.G. Anderson, Caveolin, a protein component of caveolae membrane coats., Cell. 68 (1992) 673-682. doi:10.1016/0092-8674(92)90143-Z.

[97] B.G. Galvez, S. Matias-Roman, M. Yanez-Mo, M. Vicente-Manzanares, F. Sanchez-Madrid, A.G. Arroyo, Caveolae are a novel pathway for membranetype 1 matrix metalloproteinase traffic in human endothelial cells, Mol Biol Cell. 15 (2004) 678-687. doi:10.1091/mbc.E03-07-05161rE03-07-0516 [pii].

[98] E. Frittoli, A. Palamidessi, A. Disanza, G. Scita, Secretory and endo/exocytic trafficking in invadopodia formation: The MT1-MMP paradigm, Eur. J. Cell Biol. 90 (2011) 108-114. doi:10.1016/j.ejcb.2010.04.007.

[99] L. Labrecque, C. Nyalendo, S. Langlois, Y. Durocher, C. Roghi, G. Murphy, D. Gingras, R. Béliveau, Src-mediated tyrosine phosphorylation of caveolin-1 induces its association with membrane type 1 matrix metalloproteinase, J. Biol. Chem. 279 (2004) 52132-52140. doi:10.1074/jbc.M409617200.

[100] B. Annabi, M. Lachambre, N. Bousquet-Gagnon, M. Pagé, D. Gingras, R. Béliveau, Localization of membrane-type 1 matrix metalloproteinase in caveolae membrane domains., Biochem. J. 353 (2001) 547-53. doi:10.1042/0264-6021:3530547.

[101] H. Yamaguchi, Y. Takeo, S. Yoshida, Z. Kouchi, Y. Nakamura, K. Fukami, Lipid rafts and caveolin-1 are required for invadopodia formation and extracellular 
matrix degradation by human breast cancer cells, Cancer Res. 69 (2009) 8594-8602. doi:10.1158/0008-5472.CAN-09-2305.

[102] J. Dai, M.P. Sheetz, Regulation of endocytosis, exocytosis, and shape by membrane tension, in: Cold Spring Harb. Symp. Quant. Biol., 1995: pp. 567571. doi:10.1101/SQB.1995.060.01.060.

[103] G. Apodaca, Modulation of membrane traffic by mechanical stimuli., Am. J. Physiol. Renal Physiol. 282 (2002) F179-F190.

[104] G.M.S. Ferraris, C. Schulte, V. Buttiglione, V. De Lorenzi, A. Piontini, M. Galluzzi, A. Podestà, C.D. Madsen, N. Sidenius, The interaction between UPAR and vitronectin triggers ligand-independent adhesion signalling by integrins., EMBO J. 33 (2014) 2458-72. doi:10.15252/embj.201387611.

[105] F. Margheri, A. Chillà, A. Laurenzana, S. Serratì, B. Mazzanti, R. Saccardi, M. Santosuosso, G. Danza, N. Sturli, F. Rosati, L. Magnelli, L. Papucci, L. Calorini, F. Bianchini, M. Del Rosso, G. Fibbi, Endothelial progenitor cell Dependent angiogenesis requires localization of the full-length form of UPAR in caveolae, Blood. 118 (2011) 3743-3755. doi:10.1182/blood-2011-02-338681.

[106] N.C. Gauthier, M.A. Fardin, P. Roca-Cusachs, M.P. Sheetz, Temporary increase in plasma membrane tension coordinates the activation of exocytosis and contraction during cell spreading., Proc. Natl. Acad. Sci. U. S. A. 108 (2011) 14467-72. doi:10.1073/pnas.1105845108.

[107] J. Dai, H.P. Ting-Beall, M.P. Sheetz, The secretion-coupled endocytosis correlates with membrane tension changes in RBL $2 \mathrm{H} 3$ cells., J. Gen. Physiol. 110 (1997) 1-10. doi:10.1085/jgp.110.1.1.

[108] C. Li, S. Rezania, S. Kammerer, A. Sokolowski, T. Devaney, A. Gorischek, S. Jahn, H. Hackl, K. Groschner, C. Windpassinger, E. Malle, T. Bauernhofer, W. Schreibmayer, Piezo1 forms mechanosensitive ion channels in the human MCF-7 breast cancer cell line., Sci. Rep. 5 (2015) 8364. doi:10.1038/srep08364.

[109] A.G. Kamkin, I.S. Kiseleva, V.N. Yarigin, Mechanosensitive Ion Channels, Usp. Fiziol. Nauk. 33 (2002) 29-37. doi:10.1007/BF01872883. 
[110] B. Nilius, E. Honoré, Sensing pressure with ion channels, Trends Neurosci. 35 (2012) 477-486. doi:10.1016/j.tins.2012.04.002.

[111] J. Sun, F. Lu, H. He, J. Shen, J. Messina, R. Mathew, D. Wang, A.A. Sarnaik, W.C. Chang, M. Kim, H. Cheng, S. Yang, STIM1- and Orai1-mediated Ca2+ oscillation orchestrates invadopodium formation and melanoma invasion, J. Cell Biol. 207 (2014) 535-548. doi:10.1083/jcb.201407082.

[112] C.L. Cortesio, K.T. Chan, B.J. Perrin, N.O. Burton, S. Zhang, Z.Y. Zhang, A. Huttenlocher, Calpain 2 and PTP1B function in a novel pathway with Src to regulate invadopodia dynamics and breast cancer cell invasion, J. Cell Biol. 180 (2008) 957-971. doi:10.1083/jcb.200708048.

[113] M. Baldassarre, I. Ayala, G. Beznoussenko, G. Giacchetti, L.M. Machesky, A. Luini, R. Buccione, Actin dynamics at sites of extracellular matrix degradation, Eur. J. Cell Biol. 85 (2006) 1217-1231. doi:10.1016/j.ejcb.2006.08.003.

[114] R.G. Sitrin, P.M. Pan, H.A. Harper, R.A. Blackwood, R.F. Todd 3rd, Urokinase receptor (CD87) aggregation triggers phosphoinositide hydrolysis and intracellular calcium mobilization in mononuclear phagocytes, J Immunol. 163 (1999) 6193-6200.

http://www.ncbi.nlm.nih.gov/entrez/query.fcgi?cmd=Retrieve\&db=PubMed\&dop $\mathrm{t}=$ Citation\&list_uids=10570311.

[115] T.J. Kim, J. Seong, M. Ouyang, J. Sun, S. Lu, P.H. Jun, N. Wang, Y. Wang, Substrate rigidity regulates $\mathrm{Ca} 2+$ oscillation via RhoA pathway in stem cells, J. Cell. Physiol. 218 (2009) 285-293. doi:10.1002/jcp.21598.

[116] T. Kobayashi, M. Sokabe, Sensing substrate rigidity by mechanosensitive ion channels with stress fibers and focal adhesions, Curr. Opin. Cell Biol. 22 (2010) 669-676. doi:10.1016/j.ceb.2010.08.023.

[117] D.E. Clapham, Calcium Signaling, Cell. 131 (2007) 1047-1058. doi:10.1016/j.cell.2007.11.028.

[118] W.A. Catterall, Voltage-gated calcium channels, Cold Spring Harb. Perspect. Biol. 3 (2011) 1-23. doi:10.1101/cshperspect.a003947. 
[119] A.B. Parekh, J.W. Putney, Store-operated calcium channels., Physiol. Rev. 85 (2005) 757-810. doi:10.1152/physrev.00057.2003.

[120] S.F. Pedersen, G. Owsianik, B. Nilius, TRP channels: An overview, Cell Calcium. 38 (2005) 233-252. doi:10.1016/j.ceca.2005.06.028.

[121] T. Numata, T. Shimizu, Y. Okada, Direct mechano-stress sensitivity of TRPM7 channel, Cell. Physiol. Biochem. 19 (2007) 1-8. doi:10.1159/000099187.

[122] E. Oancea, J.T. Wolfe, D.E. Clapham, Functional TRPM7 channels accumulate at the plasma membrane in response to fluid flow, Circ. Res. 98 (2006) 245253. doi:10.1161/01.RES.0000200179.29375.cc.

[123] J. Middelbeek, K. Clark, H. Venselaar, M.A. Huynen, F.N. Van Leeuwen, The alpha-kinase family: An exceptional branch on the protein kinase tree, Cell. Mol. Life Sci. 67 (2010) 875-890. doi:10.1007/s00018-009-0215-z.

[124] K. Clark, J. Middelbeek, M. V. Dorovkov, C.G. Figdor, A.G. Ryazanov, E. Lasonder, F.N. van Leeuwen, The ??-kinases TRPM6 and TRPM7, but not eEF-2 kinase, phosphorylate the assembly domain of myosin IIA, IIB and IIC, FEBS Lett. 582 (2008) 2993-2997. doi:10.1016/j.febslet.2008.07.043.

[125] K. Clark, M. Langeslag, B. van Leeuwen, L. Ran, A.G. Ryazanov, C.G. Figdor, W.H. Moolenaar, K. Jalink, F.N. van Leeuwen, TRPM7, a novel regulator of actomyosin contractility and cell adhesion., EMBO J. 25 (2006) 290-301. doi:10.1038/sj.emboj.7600931.

[126] L. Fang, C. Huang, X. Meng, B. Wu, T. Ma, X. Liu, Q. Zhu, S. Zhan, J. Li, TGF$\beta 1$-elevated TRPM7 channel regulates collagen expression in hepatic stellate cells via TGF- $\beta 1 /$ Smad pathway., Toxicol. Appl. Pharmacol. 280 (2014) 33544. doi:10.1016/j.taap.2014.08.006.

[127] W.L. Chen, A. Barszczyk, E. Turlova, M. Deurloo, B. Liu, B.B. Yang, J.T. Rutka, Z.P. Feng, H.S. Sun, Inhibition of TRPM7 by carvacrol suppresses glioblastoma cell proliferation, migration and invasion, Oncotarget. (2015). http://www.ncbi.nlm.nih.gov/pubmed/25965832.

[128] J.P. Yuan, W. Zeng, G.N. Huang, P.F. Worley, S. Muallem, STIM1 
heteromultimerizes TRPC channels to determine their function as storeoperated channels., Nat. Cell Biol. 9 (2007) 636-45. doi:10.1038/ncb1590.

[129] A. Dietrich, M. Fahlbusch, T. Gudermann, Classical transient receptor potential 1 (TRPC1): Channel or Channel regulator?, Cells. 3 (2014) 939-62. doi:10.3390/cells30x000x.

[130] C. Galán, N. Dionisio, T. Smani, G.M. Salido, J.A. Rosado, The cytoskeleton plays a modulatory role in the association between STIM1 and the Ca2+ channel subunits Orai1 and TRPC1., Biochem. Pharmacol. 82 (2011) 400-10. doi:10.1016/j.bcp.2011.05.017.

[131] G.K. Voeltz, M.M. Rolls, T.A. Rapoport, Structural organization of the endoplasmic reticulum, EMBO Rep. 3 (2002) 944-950. doi:10.1093/emboreports/kvf202.

[132] N. Borgese, M. Francolini, E. Snapp, Endoplasmic reticulum architecture: structures in flux, Curr. Opin. Cell Biol. 18 (2006) 358-364. doi:10.1016/j.ceb.2006.06.008.

[133] S.K. Parks, J. Chiche, J. Pouyssegur, pH control mechanisms of tumor survival and growth, J. Cell. Physiol. 226 (2011) 299-308. doi:10.1002/jcp.22400.

[134] V. Estrella, T. Chen, M. Lloyd, J. Wojtkowiak, H.H. Cornnell, A. IbrahimHashim, K. Bailey, Y. Balagurunathan, J.M. Rothberg, B.F. Sloane, J. Johnson, R.A. Gatenby, R.J. Gillies, Acidity generated by the tumor microenvironment drives local invasion, Cancer Res. 73 (2013) 1524-1535. doi:10.1158/00085472.CAN-12-2796.

[135] R.J. Gillies, N. Raghunand, M.L. Garcia-Martin, R.A. Gatenby, pH imaging. A review of $\mathrm{pH}$ measurement methods and applications in cancers, IEEE Eng Med.Biol.Mag. 23 (2004) 57-64.

[136] E.K. Hoffmann, I.H. Lambert, S.F. Pedersen, Physiology of cell volume regulation in vertebrates., Physiol. Rev. 89 (2009) 193-277. doi:10.1152/physrev.00037.2007.

[137] R.A. Cardone, V. Casavola, S.J. Reshkin, The role of disturbed pH dynamics 
and the $\mathrm{Na}+/ \mathrm{H}+$ exchanger in metastasis, Nat Rev Cancer. 5 (2005) 786-795. http://dx.doi.org/10.1038/nrc1713.

[138] M.R. Greco, E. Antelmi, G. Busco, L. Guerra, R. Rubino, V. Casavola, S.J. Reshkin, R.A. Cardone, Protease activity at invadopodial focal digestive areas is dependent on NHE1-driven acidic pHe, Oncol. Rep. 31 (2014) 940-946. doi:10.3892/or.2013.2923.

[139] B.T. Beaty, Y. Wang, J.J. Bravo-Cordero, V.P. Sharma, V. Miskolci, L. Hodgson, J. Condeelis, Talin regulates moesin-NHE-1 recruitment to invadopodia and promotes mammary tumor metastasis, J. Cell Biol. 205 (2014) 737-751. doi:10.1083/jcb.201312046.

[140] G. Busco, R.A. Cardone, M.R. Greco, A. Bellizzi, M. Colella, E. Antelmi, M.T. Mancini, M.E. Dell'Aquila, V. Casavola, A. Paradiso, S.J. Reshkin, NHE1 promotes invadopodial ECM proteolysis through acidification of the periinvadopodial space, FASEB J. 24 (2010) 3903-3915. doi:10.1096/fj.09149518.

[141] D. Von Lewinski, B. Stumme, L.S. Maier, C. Luers, D.M. Bers, B. Pieske, Stretch-dependent slow force response in isolated rabbit myocardium is $\mathrm{Na}+$ dependent, Cardiovasc. Res. 57 (2003) 1052-1061. doi:10.1016/S00086363(02)00830-1.

[142] S.F. Pederson, C. Varming, S.T. Christensen, E.K. Hoffmann, Mechanisms of Activation of NHE by Cell Shrinkage and by Calyculin A in Ehrlich Ascites Tumor Cells, J. Membr. Biol. 189 (2002) 67-81. doi:10.1007/s00232-001-01902.

[143] Y. Ou, P. Strege, S.M. Miller, J. Makielski, M. Ackerman, S.J. Gibbons, G. Farrugia, Syntrophin ??2 regulates SCN5A gating by a PDZ domain-mediated interaction, J. Biol. Chem. 278 (2003) 1915-1923. doi:10.1074/jbc.M209938200.

[144] C.E. Morris, P.F. Juranka, Nav channel mechanosensitivity: activation and inactivation accelerate reversibly with stretch., Biophys. J. 93 (2007) 822-833. doi:10.1529/biophysj.106.101246. 
[145] A. Beyder, J.L. Rae, C. Bernard, P.R. Strege, F. Sachs, G. Farrugia, Mechanosensitivity of Nav1.5, a voltage-sensitive sodium channel., J. Physiol. 588 (2010) 4969-85. doi:10.1113/jphysiol.2010.199034.

[146] L. Brisson, L. Gillet, S. Calaghan, P. Besson, J.-Y. Le Guennec, S. Roger, J. Gore, $\mathrm{Na}(\mathrm{V}) 1.5$ enhances breast cancer cell invasiveness by increasing NHE1dependent $\mathrm{H}(+)$ efflux in caveolae., Oncogene. 30 (2011) 2070-2076. doi:10.1038/onc.2010.574.

[147] L. Gillet, S. Roger, P. Besson, F. Lecaille, J. Gore, P. Bougnoux, G. Lalmanach, J.-Y. Le Guennec, Voltage-gated Sodium Channel Activity Promotes Cysteine Cathepsin-dependent Invasiveness and Colony Growth of Human Cancer Cells., J. Biol. Chem. 284 (2009) 8680-8691. doi:10.1074/jbc.M806891200.

[148] L. Brisson, V. Driffort, L. Benoist, M. Poet, L. Counillon, E. Antelmi, R. Rubino, P. Besson, F. Labbal, S. Chevalier, S.J. Reshkin, J. Gore, S. Roger, NaV1.5 sodium channels allosterically regulate the NHE-1 exchanger and promote breast cancer cell invadopodial activity, J Cell Sci. (2013). doi:10.1242/jcs.123901.

[149] F.H. MOHAMMED, M.A. KHAJAH, M. YANG, W.J. BRACKENBURY, Y.A. LUQMANI, Blockade of voltage-gated sodium channels inhibits invasion of endocrine-resistant breast cancer cells, Int. J. Oncol. 48 (2016) 73-83. doi:10.3892/ijo.2015.3239.

[150] M.D. Carrithers, G. Chatterjee, L.M. Carrithers, R. Offoha, U. Iheagwara, C. Rahner, M. Graham, S.G. Waxman, Regulation of podosome formation in macrophages by a splice variant of the sodium channel SCN8A, J. Biol. Chem. 284 (2009) 8114-8126. doi:10.1074/jbc.M801892200.

[151] A.G. Remacle, S. Kumar, K. Motamedchaboki, P. Cieplak, S. Hullugundi, J. Dolkas, V.I. Shubayev, A.Y. Strongin, Matrix metalloproteinase (MMP) proteolysis of the extracellular loop of voltage-gated sodium channels and potential alterations in pain signaling, J. Biol. Chem. 290 (2015) 22939-22944. doi:10.1074/jbc.C115.671107. 
[152] L.M. Coussens, B. Fingleton, L.M. Matrisian, Matrix metalloproteinase inhibitors and cancer: trials and tribulations., Science. 295 (2002) 2387-92. doi:10.1126/science.1067100. 


\section{Figure legend}

Figure 1. Schematic view of the mechanosensitive signaling pathways involved in ECM degradation. Functional interplay between mechanosensitive proteins (ion channels, integrins and F-BAR containing proteins) and proteases involved in ECM degradation via invadosome. In the upper invadosome is depicted the change in $\mathrm{pH}$ in the environment and related influx of sodium. The presence and the compartmentalization of calcium current is depicted on the lower part of the scheme. Abbreviations: MMP: matrix metalloproteinases; $\mathrm{H}^{+}$: hydrogen ion; $\mathrm{Na}^{+}$sodium ion; VGSC: voltage gated sodium channels; NHE-1: $\mathrm{Na}^{+} / \mathrm{H}^{+}$exchanger 1 ; DPP4: Dipeptidyl-Peptidase; FAPa; Fibroblasts Activation Protein a; EGFR: epidermal growth factor receptor; ADAM: A Disintegrin And Metalloproteinase; HB-EGF: ligand heparin - epidermal growth factor; uPAR: plasminogen activator receptor; Src: nonreceptor tyrosine kinase; $\mathrm{Ca}^{2+}$; calcium ion; STIM1: Stromal interaction molecule 1; ER: endoplasmatic reticulum; Orai1: Calcium release-activated calcium channel protein 1; MT1-MMP : membrane-tethered matrix metalloproteinases; TRPM7; Transient receptor potential melastatin ion channel 7 


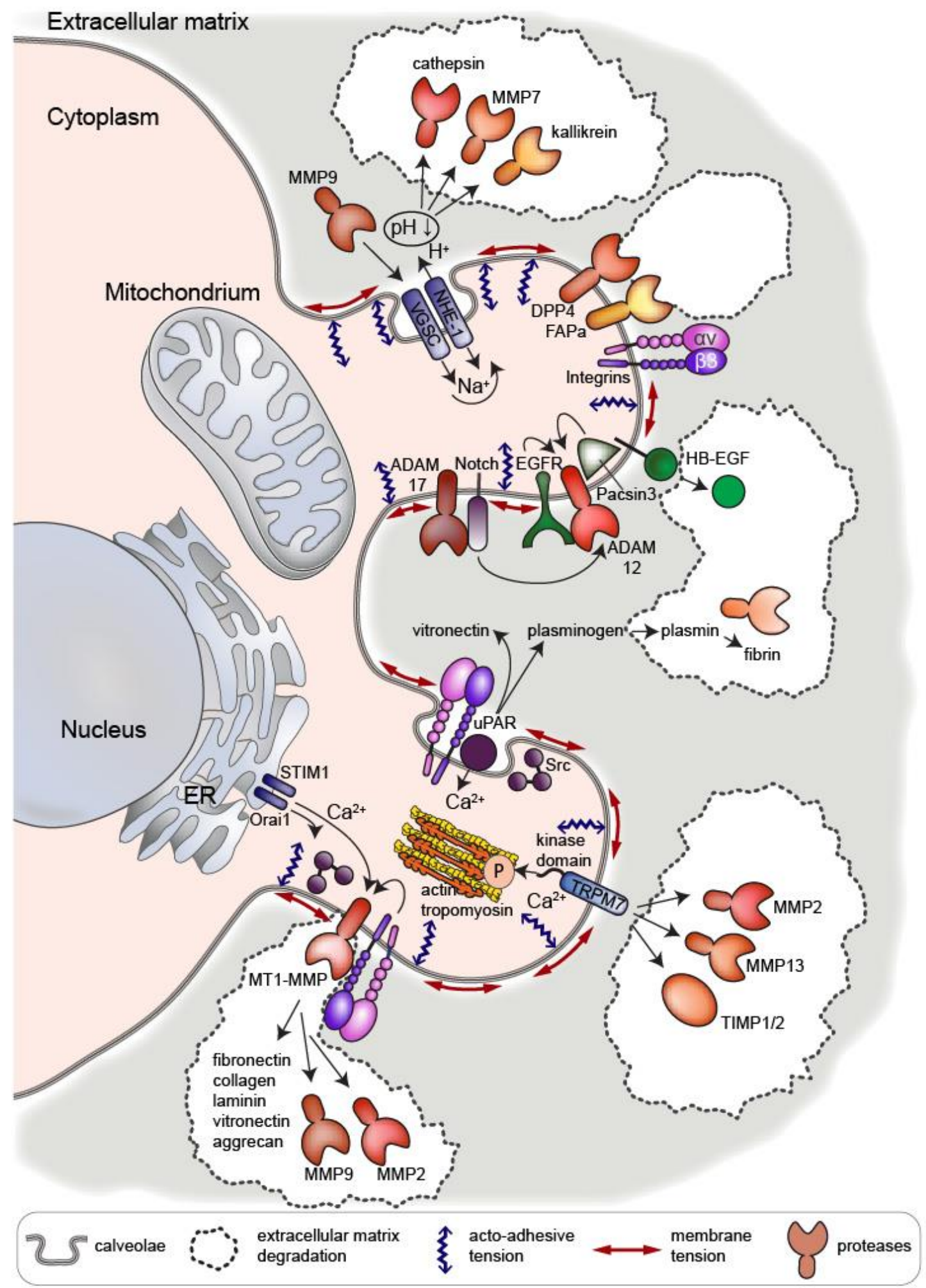

Fig1. 